\title{
Rifaximin, a non-absorbable antibiotic, inhibits the release of pro-angiogenic mediators in colon cancer cells through a pregnane $X$ receptor-dependent pathway
}

\author{
GIUSEPPE ESPOSITO $^{1 *}$, STEFANO GIGLI $^{1 *}$, LUISA SEGUELLA ${ }^{1}$, NICOLA NOBILE $^{1}$, \\ ALESSANDRA D'ALESSANDRO ${ }^{2}$, MARCELLA PESCE $^{2}$, ELENA CAPOCCIA ${ }^{1}$, LUCA STEARDO ${ }^{1}$, \\ CARLA CIRILLO $^{3}$, ROSARIO CUOMO $^{2}$ and GIOVANNI SARNELLI ${ }^{2}$
}

\author{
${ }^{1}$ Department of Physiology and Pharmacology, 'Vittorio Erspamer', La Sapienza University of Rome, I-00185 Rome; \\ ${ }^{2}$ Department of Clinical Medicine and Surgery, 'Federico II' University of Naples, I-80131 Naples, Italy; \\ ${ }^{3}$ Laboratory for Enteric NeuroScience (LENS), Translational Research Center for Gastrointestinal \\ Disorders (TARGID), University of Leuven, 3000 Leuven, Belgium
}

Received February 22, 2016; Accepted March 3, 2016

DOI: $10.3892 /$ ijo.2016.3550

\begin{abstract}
Activation of intestinal human pregnane X receptor (PXR) has recently been proposed as a promising strategy for the chemoprevention of inflammation-induced colon cancer. The present study was aimed at evaluating the effect of rifaximin, a non-absorbable antibiotic, in inhibiting angiogenesis in a model of human colorectal epithelium and investigating the role of PXR in its mechanism of action. Caco- 2 cells were treated with rifaximin $(0.1,1.0$ and $10.0 \mu \mathrm{M})$ in the presence or absence of ketoconazole $(10 \mu \mathrm{M})$ and assessed for cell proliferation, migration and expression of proliferating cell nuclear antigen (PCNA). The release of vascular endothelial growth factor (VEGF) and nitric oxide (NO), expression of Akt, mechanistic target of rapamycin (mTOR), p38 mitogen activated protein kinases (MAPK), nuclear factor $\kappa \mathrm{B}(\mathrm{NF}-\kappa \mathrm{B})$ and metalloproteinase-2 and -9 (MMP-2 and -9) were also evaluated. Treatment with rifaximin $0.1,1.0$ and $10.0 \mu \mathrm{M}$ caused significant and concentration-dependent reduction of cell proliferation, cell migration and PCNA expression in the Caco-2 cells vs. untreated cells. Treatment downregulated
\end{abstract}

Correspondence to: Dr Giovanni Sarnelli, Department of Clinical Medicine and Surgery, 'Federico II' University of Naples, Via Pansini 5, I-80131 Naples, Italy

E-mail: sarnelli@unina.it

Dr Giuseppe Esposito, Department of Physiology and Pharmacology 'Vittorio Erspamer', La Sapienza University of Rome, Piazale Aldo Moro 5, I-00185 Rome, Italy

E-mail: giuseppe.esposito@uniroma1.it

*Contributed equally

Key words: angiogenesis, Caco-2 cell line, nitric oxide, pregnane $\mathrm{X}$ receptor, rifaximin, vascular endothelial growth factor
VEGF secretion, NO release, VEGFR-2 expression, MMP-2 and MMP-9 expression vs. untreated cells. Rifaximin treatment also resulted in a concentration-dependent decrease in the phosphorylation of Akt, mTOR, p38MAPK and inhibition of hypoxia-inducible factor $1-\alpha$ (HIF-1 $\alpha$ ), p70S6K and NF- $\mathrm{KB}$. Ketoconazole (PXR antagonist) treatment inhibited these effects. These findings demonstrated that rifaximin causes PXR-mediated inhibition of angiogenic factors in Caco-2 cell line and may be a promising anticancer tool.

\section{Introduction}

Colorectal cancer (CRC) represents one of the major causes of morbidity and mortality throughout the world and is the third most common form of human cancer worldwide $(1,2)$. Like other forms of cancer, CRC is characterized by angiogenesis, which is a crucial event in promoting cancer growth, progression and metastasis (3). Among the various signaling molecules involved in the angiogenic process, vascular endothelial growth factor (VEGF) and nitric oxide (NO) are thought to be the key signaling molecules responsible for neo-vascularization (4-6). Once hypersecreted, VEGF binds to its type 2 receptor (VEGFR-2) and mediates the regulation of different pathways in the target cells, mainly the phosphatidylinositol 3-kinase (PI3K)/protein kinase B (Akt)/mammalian target of rapamycin (mTOR) pathway $(7,8)$ and the phosphop38 mitogen activated protein kinase (MAPK)-dependent activation of nuclear factor $\kappa \mathrm{B}(\mathrm{NF}-\mathrm{\kappa B})(9,10)$. Activation of the NF- $\mathrm{KB}$ and Akt/mTOR pathways increases the levels of the inducible nitric oxide synthase (iNOS) isoform, leading to the release and accumulation of nitric oxide (NO) that acts as a pro-angiogenic stimulus on the blood vessels and favors neo-vascularization in solid tumors $(5,11)$. Thus, targeting the angiogenic and mitogenic pathways is a rational and potentially effective strategy in the treatment of CRC (12).

Rifaximin is a semi-synthetic antibiotic largely used for the treatment of travelers' diarrhea and hepatic encephalopathy $(13,14)$. It is poorly absorbed on oral administration (15) 
and as such has an optimum safety profile. Apart from its antibiotic potential, rifaximin has also been studied for its anti-inflammatory effects; several studies have highlighted the anti-inflammatory potential of rifaximin, which is mainly attributed to the inhibition of the $N F-\kappa \mathrm{B}$ signaling and $\mathrm{NO}$ release via activation of intestinal human pregnane $X$ (PXR) receptors $(16,17)$.

The aim of the present study was to explore the anti-proliferative and anti-migration effects of rifaximin, and to evaluate the possible control of the angiogenic mediator release by rifaximin using a human intestinal epithelial cell line to model the intestinal barrier. The effect of rifaximin on VEGF and NO signaling and the mechanisms involved were also investigated.

\section{Materials and methods}

Caco-2 cells were purchased from the European Collection of Cell Cultures (ECACC, Public Health England Porton Down, Salisbury, UK). Cell medium, drugs and reagents for cell culture were purchased from Sigma-Aldrich (St. Louis, MO, USA), unless otherwise specified. Instruments, reagents and materials for western blot analysis were obtained from Bio-Rad Laboratories (Milan, Italy). Rifaximin and ketoconazole were purchased from Tocris Cookson, Inc. (Ballwin, MO, USA). Mouse anti-total Akt, rabbit monoclonal anti-phospho-Akt (Ser473), rabbit polyclonal anti-phospho-mTOR (pSer2448), rabbit polyclonal anti-total p70S6K, rabbit polyclonal anti-phospho-p70S6K (Thr421/Ser424, Thr389) and rabbit monoclonal anti-VEGF receptor were purchased from Cell Signaling Technology (Euroclone, Pero, Milan, Italy). Rabbit polyclonal anti-total mTOR was purchased from Abcam (Cambridge, UK); mouse monoclonal anti-hypoxia-inducible factor 1- $\alpha$ (HIF1- $\alpha$ ) was purchased from Sigma-Aldrich (Milan, Italy); rabbit polyclonal anti-matrix metalloprotease-2 and 9 (MMP-2 and MMP-9) and mouse anti- $\beta$-actin were purchased from Santa Cruz Biotechnology (Santa Cruz, CA, USA). Polyclonal rabbit anti-mouse immunoglobulin $\mathrm{G}$ was procured from Dako (Glostrup, Denmark), ${ }^{32} \mathrm{P}-\gamma$-ATP fromAmersham Biosciences (Milan, Italy), poly(deoxyinosinic-deoxycytidylic) acid (poly (dI-dC)), from Boehringer Mannheim (Milan, Italy) and horseradish peroxidase (HRP) from Dako (Milan, Italy). Chemiluminescence detection reagents were purchased from Amersham Biosciences and custom oligonucleotides were synthesized by TIB Molbiol (Boehringer-Mannheim, Mannheim, Germany).

Cell culture. Caco-2 cells were cultured in 6-well plates in Dulbecco's modified Eagle's medium (DMEM) containing $10 \%$ fetal bovine serum (FBS), $1 \%$ penicillin-streptomycin, $2 \mathrm{mM}$ L-glutamate and $1 \%$ non-essential amino acids. A total of $1 \times 10^{6}$ cells/well were plated and incubated for $24 \mathrm{~h}$. Upon reaching confluence, the cells were washed three times with phosphate-buffered saline (PBS), detached with trypsin/ethylene diamine tetraacetic acid (EDTA), plated in $10-\mathrm{cm}$ diameter petri dishes and allowed to adhere for $24 \mathrm{~h}$. Subsequently, DMEM was replaced with fresh medium and cells were treated for $72 \mathrm{~h}$ with increasing concentrations of rifaximin $(0.1,1.0$ and $10.0 \mu \mathrm{M})$ dissolved in ultrapure and pyrogen-free sterile vehicle in the presence or absence of the PXR antagonist ketoconazole $(10 \mathrm{mM})$ at different time-points depending upon the experiments. Rifaximin and ketoconazole concentrations were selected based on the data from the available literature $(16,18)$ and the pilot experiments (data not shown) that helped in identifying the lowest effective concentrations.

Western blot analysis. Protein expression in the Caco-2 cells was evaluated by western blot analysis. After the different treatments, cells $\left(1 \times 10^{6}\right)$ were harvested, washed twice with ice-cold PBS and centrifuged at $180 \mathrm{x}$ g for $10 \mathrm{~min}$ at $4{ }^{\circ} \mathrm{C}$. The cell pellet obtained after centrifugation was re-suspended in $100 \mu \mathrm{l}$ ice-cold hypotonic lysis buffer (10 mM HEPES, $1.5 \mathrm{mM} \mathrm{MgCl}{ }_{2}, 10 \mathrm{mM} \mathrm{KCl}, 0.5 \mathrm{mM}$ phenylmethylsulphonylfluoride, $1.5 \mu \mathrm{g} / \mathrm{ml}$ soybean trypsin inhibitor, $7 \mu \mathrm{g} / \mathrm{ml}$ pepstatin A, $5 \mu \mathrm{g} / \mathrm{ml}$ leupeptin, $0.1 \mathrm{mM}$ benzamidine and $0.5 \mathrm{mM}$ DTT). To lyse the cells, the suspension was rapidly passed through a syringe needle five to six times and then centrifuged for $15 \mathrm{~min}$ at $13,000 \mathrm{x}$ g to obtain the cytoplasmic fraction. The cytoplasmic fraction proteins were mixed with non-reducing gel loading buffer [50 mM Tris, $10 \%$ sodium dodecyl sulphate (SDS), $10 \%$ glycerol, $2 \mathrm{mg}$ bromophenol $/ \mathrm{ml}]$ at a 1:1 ratio, boiled for $3 \mathrm{~min}$ and centrifuged at $10,000 \mathrm{x} \mathrm{g}$ for $10 \mathrm{~min}$. The protein concentration was determined using the Bradford assay and $50 \mu \mathrm{g}$ of each sample was electrophoresed on a $12 \%$ discontinuous polyacrylamide mini-gel. Proteins were then transferred onto nitrocellulose membranes that had been saturated by incubation with $10 \%$ non-fat dry milk in 1X PBS overnight at $4^{\circ} \mathrm{C}$ with the following antibodies: total Akt $(1: 1,000)$, phospho-Akt $(1: 2,000)$, total mTOR $(1: 1,000)$, phospho-mTOR $(1: 1,000)$, total p70S6K $(1: 1,000)$, phosphop70S6K (1:1,000), anti-HIF-1 $\alpha$ (1:500), anti-iNOS $(1: 1,000)$, anti-VEGFR-2 (1:1,000), anti-MMP-2 (1:1,000), anti-MMP-9 $(1: 1,000)$, anti-phospho-p38 (1:1,000), and anti- $\beta$-actin protein expression was performed on total protein fractions of homogenates. Membranes were then incubated with the specific secondary antibodies conjugated to HRP. Immune complexes were identified by enhanced chemiluminescence detection reagents and blots were analyzed by scanning densitometry (GS-700 imaging densitometer; Bio-Rad Laboratories). Results were expressed as optical density (OD) (arbitrary units; $\mathrm{mm}^{2}$ ) and normalized against the expression of the housekeeping protein $\beta$-actin.

Electrophoretic mobility shift assay. Electrophoretic mobility shift assay (EMSA) was performed to detect NF- $\kappa \mathrm{B}$ activation in Caco-2 cells. Briefly, $10 \mathrm{mg}$ of the cell extracts were incubated in a binding buffer (8 mM HEPES, pH 7.0, $10 \%$ glycerol, $20 \mathrm{mM} \mathrm{KCl}, 4 \mathrm{mM} \mathrm{MgCl}{ }_{2}, 1 \mathrm{mM}$ sodium pyrophosphate) containing $1.0 \mathrm{mg}$ of poly $(\mathrm{dI}-\mathrm{dC})$ and ${ }^{32} \mathrm{P}-\gamma$ end-labeled probe with the following sequence: i) 5' AAC TCC GGG AAT TTC CCT GGC CC 3' and ii) 5' GGG CCA GGG AAA TTC CCG GAG TT 3'. Nuclear extracts were incubated for $15 \mathrm{~min}$ with radiolabelled oligonucleotides $\left(2.5-5.0 \times 10^{4} \mathrm{cpm}\right)$ in $20 \mathrm{ml}$ reaction buffer containing $2 \mathrm{mg}$ poly(dI-dC), $10 \mathrm{mM}$ Tris- $\mathrm{HCl}$ (pH 7.5), $100 \mathrm{mM} \mathrm{NaCl}, 1 \mathrm{mM}$ EDTA, $1 \mathrm{mM}$ DL-dithiothreitol, $1 \mathrm{mg} / \mathrm{ml}$ bovine serum albumin (BSA) and 10\% (v/v) glycerol. Nuclear protein-oligonucleotide complexes were resolved by electrophoresis on a $6 \%$ non-denaturing polyacrylamide gel in a Tris-borate-EDTA buffer at $150 \mathrm{~V}$ for $2 \mathrm{~h}$ at $4^{\circ} \mathrm{C}$. The gel was dried and autoradiographed with an intensifying screen at $-80^{\circ} \mathrm{C}$ for $20 \mathrm{~h}$. The relative bands were 
quantified by densitometric scanning using VersaDoc (BioRad Laboratories) and a computer program (Quantity One Software; Bio-Rad Laboratories).

Nitric oxide quantification. $\mathrm{NO}$ was measured as nitrite $\left(\mathrm{NO}_{2}^{-}\right)$ accumulation in the homogenates derived from Caco-2 cells by a spectrophotometric assay based on the Griess reaction. Griess reagent ( $1 \%$ sulphanilamide in $\mathrm{H}_{2} \mathrm{O}$ plus $0.1 \%$ naphthyl ethylenediamine in $\mathrm{H}_{3} \mathrm{PO}_{4}$ ) was added to an equal volume of supernatant and the absorbance was measured at $550 \mathrm{~nm}$. Nitrite concentration (nM) was determined using a standard curve of $\mathrm{NaNO}_{2}$.

Cell proliferation assay. Cell proliferation was evaluated by performing a 3-[4,5-dimethylthiazol-2-yl]-2,5-diphenyl tetrazolium bromide (MTT) assay (19). Caco-2 cells $\left(5 \times 10^{4}\right)$ were plated in 96-well plates and allowed to adhere for $3 \mathrm{~h}$. DMEM was then replaced with fresh medium and the cells were untreated or treated with increasing concentrations of rifaximin $(0.1,1$ and $10 \mu \mathrm{M})$ in the presence or absence of ketoconazole $(10 \mathrm{mM})$. After $48 \mathrm{~h}, 25 \mu \mathrm{l}$ MTT $(5 \mathrm{mg} / \mathrm{ml}$ MTT in DMEM) was added to the cells and the mixture was incubated for further $3 \mathrm{~h}$ at $37^{\circ} \mathrm{C}$. Cells were then lysed and the dark blue crystals were solubilized using a $125 \mu \mathrm{l}$ solution containing $50 \% \mathrm{~N}, \mathrm{~N}$-dimethyl formamide and $20 \%(\mathrm{w} / \mathrm{v})$ SDS ( $\mathrm{pH} 4.5$ ). The OD of each well was determined using a Perkin-Elmer, Inc. (Waltham, MA, USA) microplate spectrophotometer equipped with a $620-\mathrm{nm}$ filter. Cell proliferation in response to treatment was calculated using the following equation: Cell proliferation at $48 \mathrm{~h}(\%)=(\mathrm{OD}$ treated $/ \mathrm{OD}$ untreated) x 100 .

Wound healing assay. The wound healing assay was performed as previously described by Renault-Mihara and colleagues, with some modifications (20). Briefly, Caco-2 cells were plated on a 6 -well plate and allowed to adhere to the surface of the wells. The cells were then scratched using a $200-\mu 1$ sterile pipette tip, washed with PBS and incubated with rifaximin (0.1-10 $\mu \mathrm{M})$ for $48 \mathrm{~h}$. After incubation, the cells were again washed twice with PBS and fixed with $4 \%$ paraformaldehyde for $30 \mathrm{~min}$. The cells were washed three times with PBS and photographed in a bright field using a Nikon Eclipse 80 (Nikon Instruments Europe, Kingston, UK) microscope equipped with a high-resolution digital camera (Nikon Digital Sight DS-U1; Nikon Corp.). The percentage of migration was calculated by counting the number of cells that migrated into scratched areas compared with cells that stayed in the peripheral areas.

Enzyme-linked immunosorbent assay. Enzyme-linked immunosorbent assay (ELISA) for mouse VEGF (Abcam, Cambridge, UK) was carried out on Caco-2 cell supernatant at 24-h post treatment, according to the manufacturer's protocol. Absorbance was measured on a microtiter plate reader. VEGF levels were determined using the standard curve method.

Proliferating cell nuclear antigen immunofluorescence. Caco-2 cells were plated onto glass slide chambers coated with poly-D-lysine $\left(3 \times 10^{4}\right.$ cells/well) and incubated for $24 \mathrm{~h}$ in the presence of rifaximin with or without ketoconazole.
After the treatment, cells were washed with PBS-Triton $0.1 \%$ (T-PBS), fixed in 4\% paraformaldehyde and then incubated in $10 \% \mathrm{BSA} / 0.1 \% \mathrm{~T}$-PBS solution for $90 \mathrm{~min}$ and for $1 \mathrm{~h}$ with a $10 \% \mathrm{BSA} / 0.1 \%$ T-PBS solution of anti-proliferating cell nuclear antigen (PCNA) antibody 1:100 (Abcam) for immunostaining. Finally, the cells were incubated for $1 \mathrm{~h}$ in the dark with fluorescein isothiocyanate conjugated anti-rabbit antibody 1:100 (Abcam). Nuclei were stained using Hoechst stain $(1: 5,000)$ (Sigma-Aldrich) and images were captured using a camera (Nikon digital sight DS-U1) connected to a microscope (Nikon eclipse 80i; Nikon Instruments Europe). The analysis of RGB intensity was performed using NIH software and quantification of $\mathrm{PCNA}^{+}$proliferating cells was expressed as \% of $\mathrm{PCNA}^{+}$expressing cells per selected area $\left(1 \mathrm{~mm}^{2}\right)$.

Statistical analysis. Results were expressed as mean \pm SEM of $n=4$ experiments in triplicate. Statistical analysis was performed using parametric one way analysis of variance (ANOVA) and multiple comparisons were performed using Bonferroni's post hoc test. P-values $<0.05$ were considered to indicate a statistically significant result.

\section{Results}

Cell proliferation in Caco-2 cells. The effect of rifaximin treatment on cell proliferation and PCNA expression is shown in Fig. 1. Rifaximin $0.1,1$ and $10 \mu \mathrm{M}$ caused a significant and concentration-dependent reduction in Caco-2 cell proliferation $(-25,-40$ and $-68 \%$ vs. untreated cells; Fig. 1A), and this effect was inhibited by ketoconazole. Similarly, the expression of PCNA was reduced in a concentration-dependent manner by rifaximin $0.1,1$ and $10 \mu \mathrm{M}(-29,-53$ and $-76 \%$ vs. untreated cells; Fig. 1B and C) and completely abolished by ketoconazole.

Cell migration, VEGF secretion, and VEGFR-2, MMP-2 and $M M P-9$ expression. The wound healing assay was used to evaluate the effect of rifaximin on Caco-2 cell migration. As indicated in panel 1 of Fig. 2A, untreated Caco-2 cells were able to invade and fully recolonize the scratched area within $48 \mathrm{~h}$ of treatment. In contrast, the migration of cells treated with rifaximin $0.1,1$ and $10 \mu \mathrm{M}$ was significantly reduced in a concentration-dependent manner (-18, -30 and $-46 \%$, vs. untreated cells) (Fig. 2B). Also, the distances between the borders of the wound were significantly different compared to those measured in the untreated cells (Fig. 2A, panels 2, 3 and 4). The anti-migratory effect of rifaximin was completely counteracted by ketoconazole (Fig. 2A, panel 5).

As shown in Fig. 2, incubation with rifaximin 0.1, 1 and $10 \mu \mathrm{M}$ resulted in a significant downregulation of pro-angiogenic mediators released at $48 \mathrm{~h}$, causing a significant and concentration-dependent decrease of both VEGF secretion and NO release $(-32,-45-72$ and $-40,-69$ and $-87 \%$, respectively, vs. untreated cells) (Fig. 2C and D). Similarly, rifaximin incubation significantly reduced the expression of VEGFR-2 and iNOS protein $(-33-58,-65$ and $-40,-69,-78 \%$, respectively, vs. untreated cells) (Fig. 2E-G). Moreover, the treatment caused a significant and concentration-dependent inhibition of PXR-mediated MMP-2 and MMP-9 protein expression (-25, 

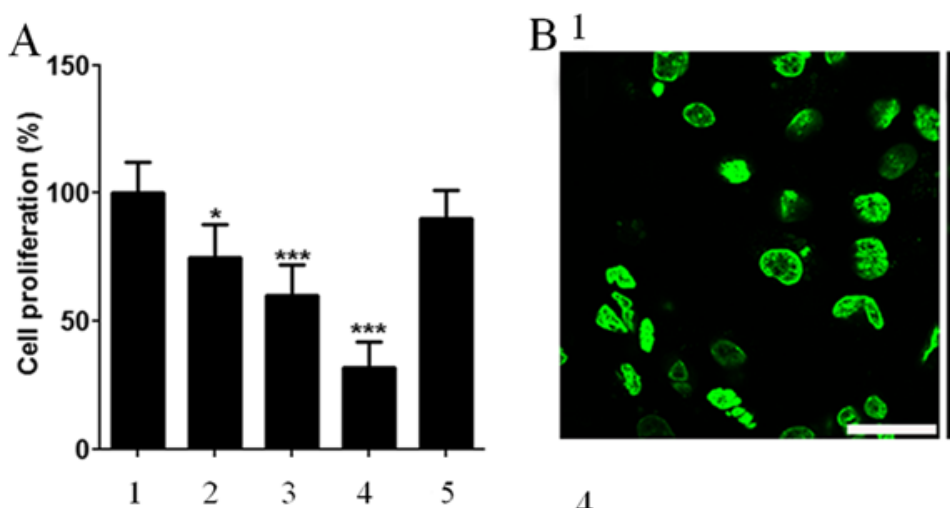

2

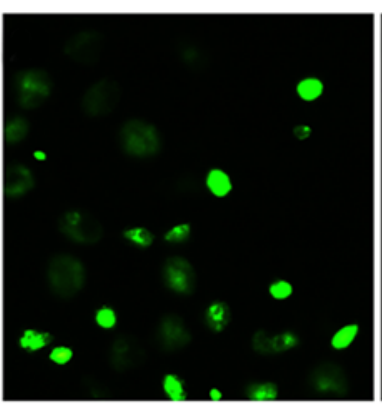

3

4

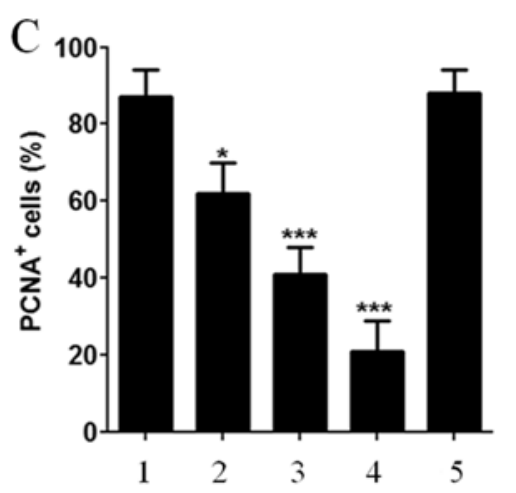

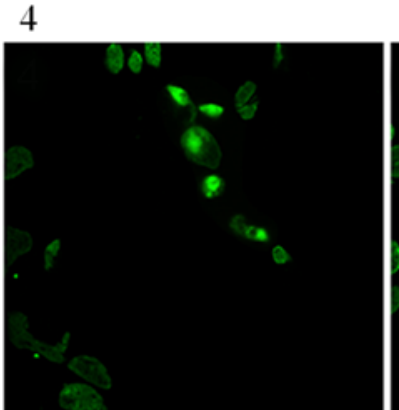

5

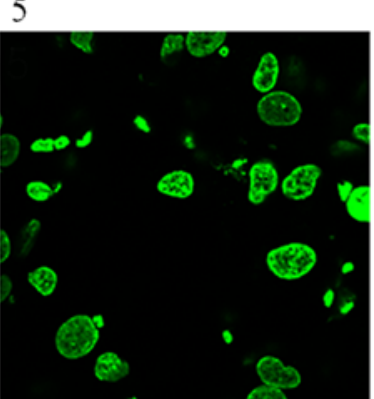

1. Vehicle

2. Rifaximin $0.1 \mu \mathrm{M}$

3. Rifaximin $1.0 \mu \mathrm{M}$

4. Rifaximin $10 \mu \mathrm{M}$

5. Rifaximin $10 \mu \mathrm{M}+$ Ketoconazole $10 \mu \mathrm{M}$

Figure 1. Rifaximin (0.1-10 $\mu \mathrm{M})$ exerts antiproliferative effects on Caco-2 cell line through a PXR-dependent selective involvement. (A) MTT analysis showing the effect of rifaximin plus ketoconazole $(10 \mu \mathrm{M})$ on Caco-2 cell proliferation; (B) immunofluorescence analysis of PCNA ${ }^{+}$positive Caco-2 cells; and (C) relative quantification in Caco-2 cells exposed to rifaximin in the presence or absence of ketoconazole (10 $\mu \mathrm{M})$ (scale bar, $50 \mu \mathrm{m})$. Results are expressed as mean \pm SEM of $n=5$ experiments performed in triplicate. ${ }^{* * *} \mathrm{P}<0.001 ;{ }^{* *} \mathrm{P}<0.01$ and ${ }^{*} \mathrm{P}<0.05$ vs. untreated Caco- 2 cells.

$-62,-87$ and $-38,-56$ and $-78 \%$, respectively, vs. untreated cells) (Fig 2E, H and I).

Akt/mTOR/p70S6K/HIF-la and p38MAPK/NF- $\kappa B$ expression . In order to further characterize the mechanisms underlying the effect of rifaximin, the involvement of the Akt/mTOR/ p70S6K pathway was evaluated. Treatment with rifaximin 0.1 , 1 and $10 \mu \mathrm{M}$ resulted in a PXR-mediated and concentrationdependent decrease in Akt phosphorylation (-50 -75 and -86\% vs. untreated cells) and a significant reduction in the phosphorylation rates of mTOR $(-38,-56$ and $-78 \%$ vs. untreated cells). Inhibition of p70S6K (-27, -55 and $-85 \%$ vs. untreated cells; Fig. 3A-D) was also seen at $24 \mathrm{~h}$ after rifaximin $0.1,1$ and $10 \mu \mathrm{M}$ treatment. Rifaximin also caused a significant and concentration-dependent decrease in HIF-1 $\alpha(-65,-82$ and $-92 \%$ vs. untreated cells); this effect was counteracted by ketoconazole. Rifaximin $0.1,1$ and $10 \mu \mathrm{M}$ significantly blocked p38MAPK-phosphorylation (-24, -62 and $-71 \%$ vs. untreated cells; Fig $3 \mathrm{~F}$ and $\mathrm{G}$ ) and inhibited NF- $\mathrm{KB}$ nuclear activation $(-29,-55$ and $-61 \%$ vs. untreated cells; Fig. $3 \mathrm{H}$ and I) as seen by EMSA analysis; inhibition was significantly reversed by ketoconazole treatment.

\section{Discussion}

In the present study, rifaximin caused a concentration-dependent reduction of Caco-2 cell proliferation and expression of PCNA vs. untreated cells. The migration of cells and the expression of VEGF, VEGFR-2, NOS and iNOS were also reduced in a concentration-dependent manner after treatment. Rifaximin significantly blocked p38MAPK-phosphorylation, inhibited NF- $\kappa \mathrm{B}$ nuclear activation and p70S6K in Caco-2 cells. Moreover, MMP-2 and MMP-9 levels, Akt phosphorylation, mTOR phosphorylation and HIF-1 $\alpha$ expression were also reduced in a concentration-dependent manner.

PCNA is a marker of cell division and its overexpression is associated with malignancy, infiltration of the vasculature and tumor metastasis (21). It is considered to be a biomarker of colorectal cancer (22). In this study, rifaximin caused a progressive reduction of Caco-2 cell proliferation and downregulated PCNA expression, thus, confirming its antiproliferative effect. This effect was counteracted by the selective PXR antagonist ketoconazole, suggesting a PXR-dependent control of carcinoma cell growth rate.

The results of the present study also showed that rifaximin effectively prevented the release of pro-angiogenic mediators in Caco-2 cells and reduced the levels of VEGF, NO, VEGFR and iNOS. Rifaximin-induced p38MAPK/NF- $\kappa B$ inhibition and reduction in HIF-1 $\alpha$ levels were significantly reversed by ketoconazole, further confirming the involvement of PXR. HIF- $1 \alpha$ is a transcriptional modulator of pro-angiogenic factor release and its expression is increased upon activation of the Akt/mTOR pathway (23). Based on the results of the present study, it can be stated that rifaximin acted at the 
A
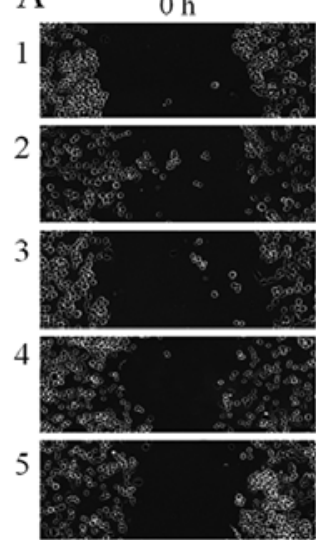

1. Vehicle

2. Rifaximin $0.1 \mu \mathrm{M}$

3. Rifaximin $1.0 \mu \mathrm{M}$

4. Rifaximin $10 \mu \mathrm{M}$

5. Rifaximin $10 \mu \mathrm{M}+$ Ketoconazole $10 \mu \mathrm{M}$
B
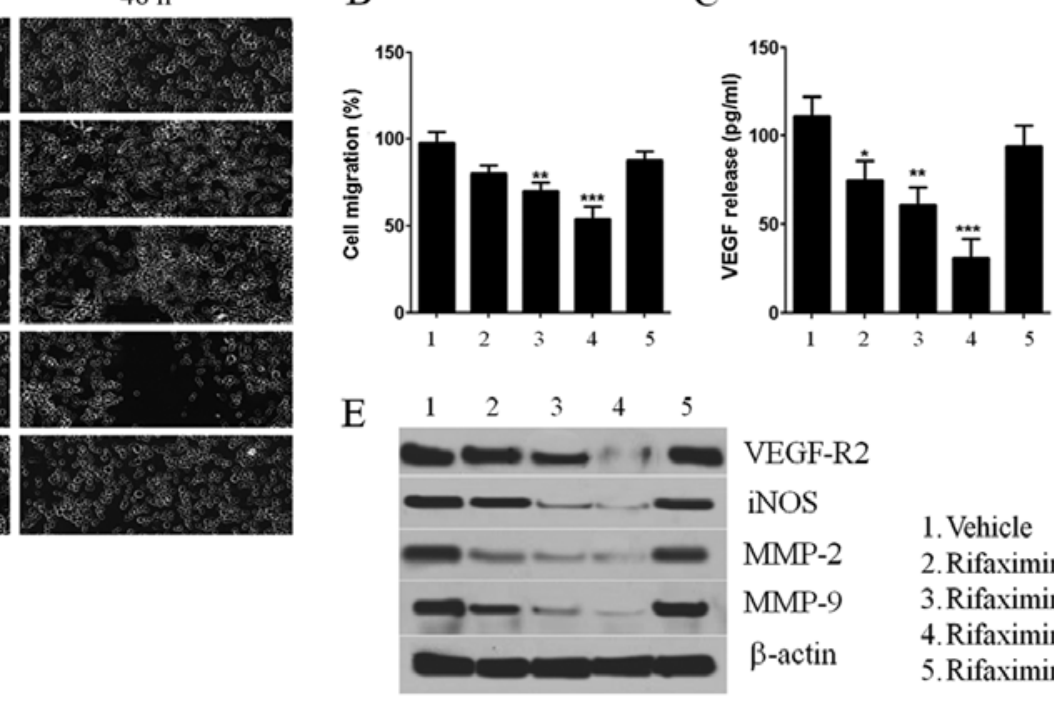

D

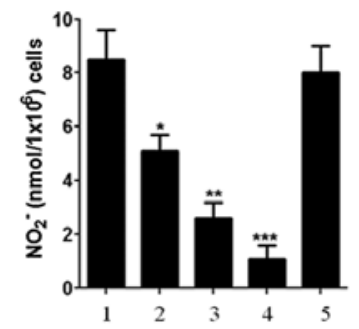

\section{VEGF-R2}

4. Rifaximin $10 \mu \mathrm{M}$
F

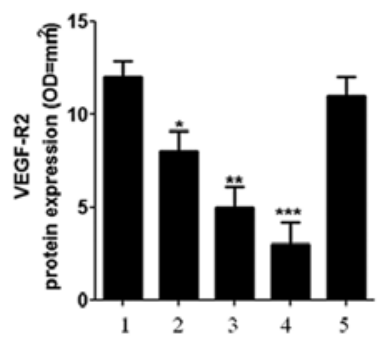

$\mathrm{H}$

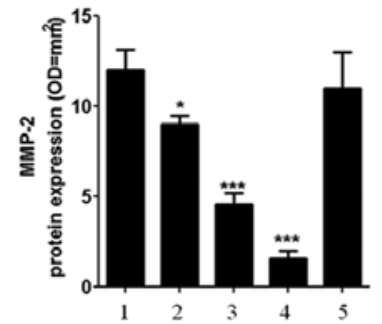

iNOS

1.Vehicle

2. Rifaximin $0.1 \mu \mathrm{M}$

3. Rifaximin $1.0 \mu \mathrm{M}$

5. Rifaximin $10 \mu \mathrm{M}+$ Ketoconazole $10 \mu \mathrm{M}$

G

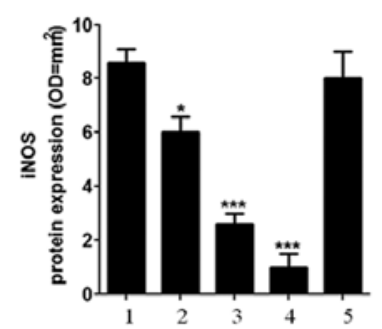

I

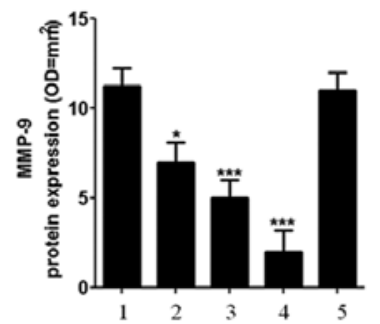

Figure 2. The anti-migration and anti-angiogenic effect of rifaximin in Caco-2 cells depends on PXR-dependent activation. (A) Wound healing assay showing the effect of rifaximin on Caco-2 cell migration in vitro. Bright field microscopy indicated that rifaximin inhibited Caco-2 cell migration in a concentration- and PXR-dependent manner (scale bar, $200 \mu \mathrm{m}$ ); (B) quantification of cell migration (\%); (C and D) rifaximin concentration-dependently inhibited pro-angiogenic release of VEGF and NO by a PXR-dependent pathway; (E) rifaximin inhibited VEGFR-2, iNOS, MMP-2 and MMP-9 protein expression in a concentration-dependent manner; and (F-I) densitometric analysis and relative quantification of corresponding immunoreactive bands for VEGFR-2, iNOS, MMP-2 and MMP-9 (normalized against the expression of the housekeeping protein $\beta$-actin). Results are expressed as mean \pm SEM of $n=5$ experiments performed in triplicate ${ }^{* * *} \mathrm{P}<0.001 ;{ }^{* *} \mathrm{P}<0.01$ and ${ }^{*} \mathrm{P}<0.05$ vs. untreated Caco- 2 cells.

PXR site and further inhibited the release of VEGF and NO by negatively interfering with both $\mathrm{p} 38 \mathrm{MAPK} / \mathrm{NF}-\kappa \mathrm{B}$ and p-Akt/p-mTOR-dependent signaling pathways. Specifically, rifaximin markedly reduced the phosphorylation of Akt, mTOR and p70S6K proteins in Caco-2 cells, leading to inhibition of HIF- $1 \alpha$ and blocking of the p38MAPK/ERK phosphorylation signaling pathway, reducing the activation of NF- $\kappa$ B. Also, rifaximin resulted in a significant and PXR-dependent decrease in the expression of MMP-2 and MMP-9 in Caco-2 cells. MMPs are involved in the growth and metastasis of cancer, specifically by promoting angiogenesis, degrading the matrix barriers and causing cell migration and proliferation (24). Thus, inhibition of MMP-2 and MMP-9 by rifaximin might be responsible for the observed reduction in the migration of Caco-2 cells in vitro.
Additionally, inhibition of both NO and VEGF secretion by rifaximin may be responsible for the consistent reduction of both iNOS and VEGFR expression in the experimental setting. Cheng et al (16) studied the anti-inflammatory effect of rifaximin in a colitis model and showed that rifaximin acted on human PXR and caused NF- $\mathrm{NB}$ inhibition. Another study demonstrated that rifaximin induced specific activation of PXR in PXR-humanized mice and mediated the inflammation, cancer cell proliferation and pro-apoptotic events in colon cancer (25). The results from the present study are in line with these reports and further show that rifaximin is a potent inhibitor of the release of angiogenic mediators.

One of the greatest advantages of this antibiotic is its poor oral absorption and an optimum safety profile $(23,26)$; the 

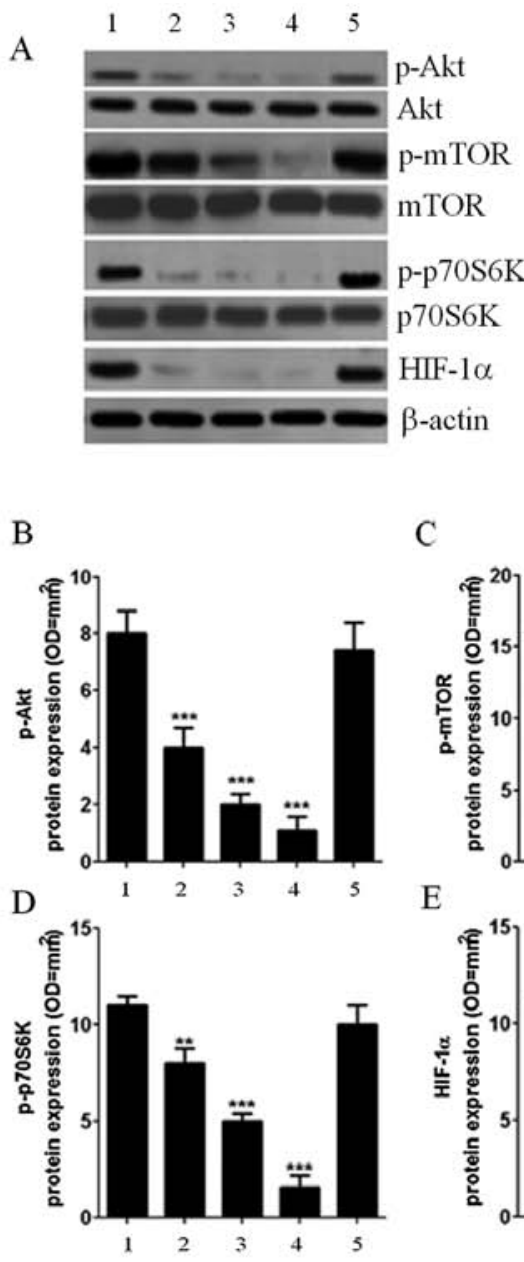

$\mathrm{C}$

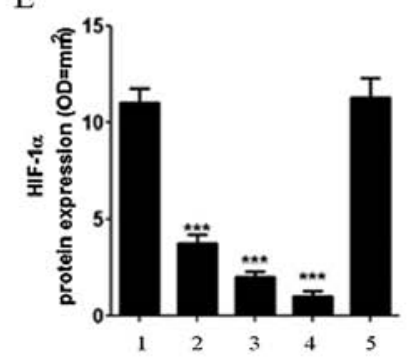

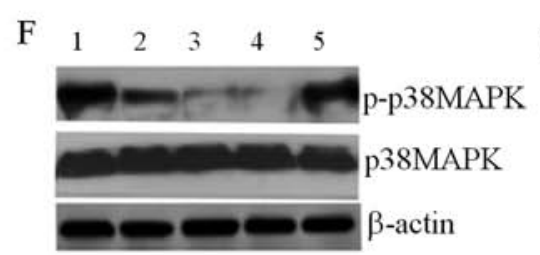
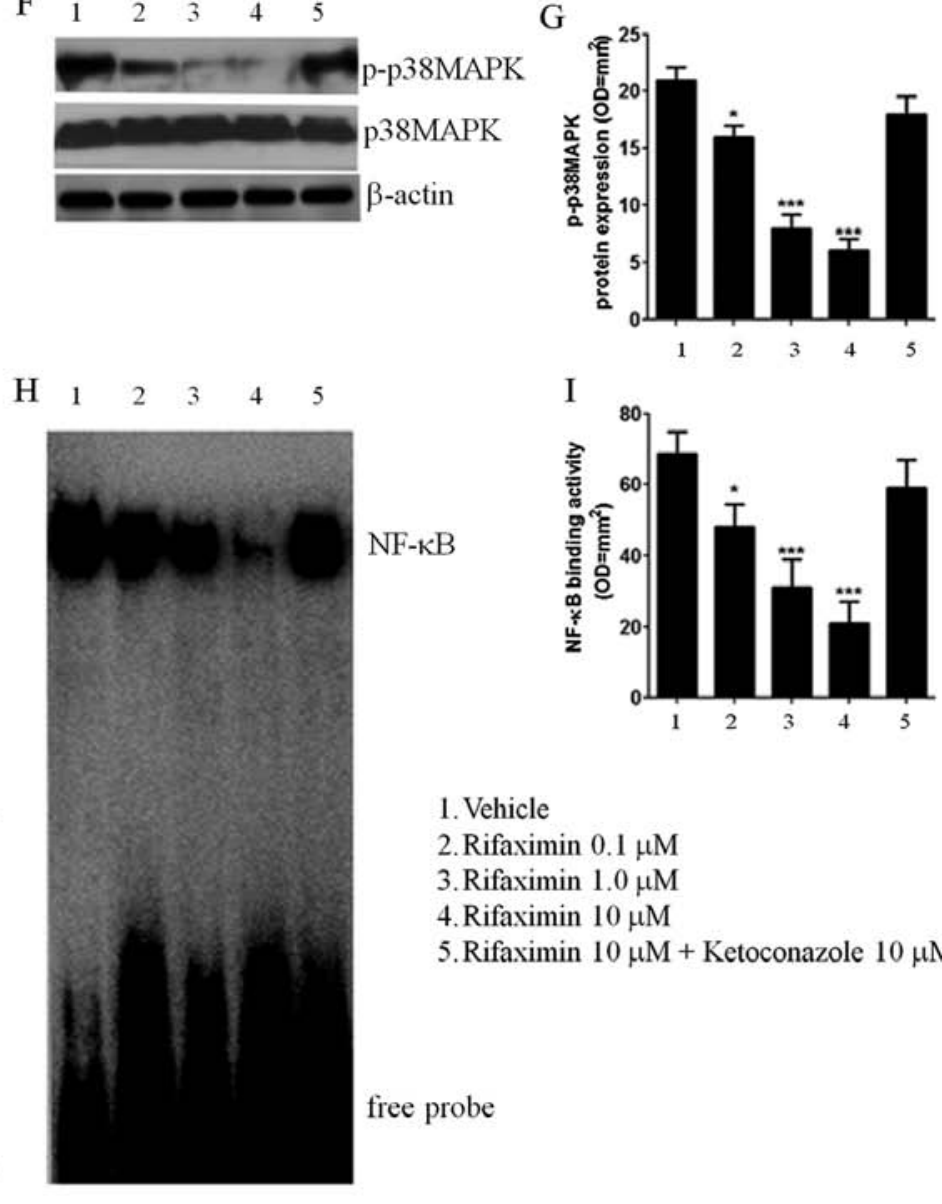

1. Vehicle

2. Rifaximin $0.1 \mu \mathrm{M}$

3. Rifaximin $1.0 \mu \mathrm{M}$

4. Rifaximin $10 \mu \mathrm{M}$

5. Rifaximin $10 \mu \mathrm{M}+$ Ketoconazole $10 \mu \mathrm{M}$

Figure 3. Rifaximin (0.1-10 $\mu \mathrm{M})$ downregulated Akt/mTOR and p38MAPK/NF- $\mathrm{BB}$ pathways through a PXR-dependent mechanism. (A) Immunoblot of phosphorylated/unphosphorylated Akt, mTOR, p70S6K and HIF-1 $\alpha$ protein bands; (B-E) relative densitometric analysis (normalized against the expression of the housekeeping protein $\beta$-actin) showing the effects of rifaximin, given alone or in the presence of ketoconazole $(10 \mu \mathrm{M})$, on the expression of Akt, mTOR and p70S6K phosphorylated proteins and HIF-1 $\alpha$ pro-angiogenic modulator in Caco-2 cells, (F) rifaximin inhibited p38MAPK phosphorylation as seen by immunoblot and EMSA analysis; (H) relative NF- $\mathrm{KB}$ activation in a concentration- and PXR-dependent manner; and (G-I) relative densitometric analysis of p38 MAPK and NF- $\kappa B$ bands (normalized against the expression of the housekeeping protein $\beta$-actin). Results are expressed as mean \pm SEM of $n=5$ experiments performed in triplicate. ${ }^{* * *} \mathrm{P}<0.001$ and ${ }^{*} \mathrm{P}<0.05$ vs. untreated $\mathrm{Caco}-2$ cells.

unabsorbed drug stays in the gut, specifically in the colon, long enough to locally exert its effects without any adverse events.

Anti-angiogenic approaches in the treatment of colon cancer have been extensively studied in the past decade, following US Food and Drug Administration approval of the first anti-VEGF monoclonal antibody, bevacizumab $(27,28)$. Despite their indisputable advantages as anticancer therapy, anti-angiogenic compounds are limited by the complexity of the converging pro-angiogenic pathways responsible for the neo-vascularization process that makes angiogenesis in cancer difficult to control, especially when the tumor starts developing and metastasizing. This limits the use of anti-VEGF drugs, unless they are used in combination with traditional chemotherapy (29-31). Drugs capable of interfering with the different steps of the pro-angiogenic and proliferative processes in cancer cells are of special interest in an attempt to identify an effective treatment. The results of the present study indicate that rifaximin efficiently mediates the synergic inhibition of multiple converging pathways involved in the growth of cancer cells, pro-angiogenic mediator release and tissue remodeling/ invasion that could markedly increase the efficacy of the anticancer therapy in CRC, when used in combination with VEGF inhibitors. Based on the promising results seen with rifaximin in vitro, further in vivo studies investigating a possible multitherapeutic approach with rifaximin plus traditional VEGF inhibitors in CRC are warranted.

\section{Acknowledgements}

The authors would like to thank Nishad Parkar of Springer Healthcare Communications for providing English and scientific editing of the manuscript before submission. This medical writing assistance was funded by Alfa Wasserman. C.C. is post-doctoral fellow of the Fonds voor Wetenschappelijk Onderzoek (FWO, Belgium).

\section{References}

1. Boyle $\mathrm{P}$ and Langman JS: ABC of colorectal cancer: Epidemiology. BMJ 321: 805-808, 2000. 
2. Haggar FA and Boushey RP: Colorectal cancer epidemiology Incidence, mortality, survival, and risk factors. Clin Colon Rectal Surg 22: 191-197, 2009.

3. Carmeliet P and Jain RK: Angiogenesis in cancer and other diseases. Nature 407: 249-257, 2000.

4. Scaldaferri F, Vetrano S, Sans M, Arena V, Straface G, Stigliano E, Repici A, Sturm A, Malesci A, Panes J, et al: VEGF-A links angiogenesis and inflammation in inflammatory bowel disease pathogenesis. Gastroenterology 136: 585-595.e585, 2009.

5. Ambs S, Merriam WG, Bennett WP, Felley-Bosco E, Ogunfusika MO, Oser SM, Klein S, Shields PG, Billiar TR and Harris CC: Frequent nitric oxide synthase-2 expression in human colon adenomas: Implication for tumor angiogenesis and colon cancer progression. Cancer Res 58: 334-341, 1998.

6. Lala PK and Chakraborty C: Role of nitric oxide in carcinogenesis and tumour progression. Lancet Oncol 2: 149-156, 2001.

7. Karar J and Maity A: PI3K/AKT/mTOR pathway in angiogenesis. Front Mol Neurosci 4: 51, 2011.

8. Pratheeshkumar P, Sreekala C, Zhang Z, Budhraja A, Ding S, Son YO, Wang X, Hitron A, Hyun-Jung K, Wang L, et al: Cancer prevention with promising natural products: Mechanisms of action and molecular targets. Anticancer Agents Med Chem 12: $1159-1184,2012$

9. Gee E, Milkiewicz M and Haas TL: p38 MAPK activity is stimulated by vascular endothelial growth factor receptor 2 activation and is essential for shear stress-induced angiogenesis. J Cell Physiol 222: 120-126, 2010.

10. Olsson AK, Dimberg A, Kreuger J and Claesson-Welsh L: VEGF receptor signalling - in control of vascular function. Nat Rev Mol Cell Biol 7: 359-371, 2006.

11. Cianchi F, Cortesini C, Fantappiè O, Messerini L, Schiavone N, Vannacci A, Nistri S, Sardi I, Baroni G, Marzocca C, et al: Inducible nitric oxide synthase expression in human colorectal cancer: Correlation with tumor angiogenesis. Am J Pathol 162: 793-801, 2003.

12. Reinacher-Schick A, Pohl M and Schmiegel W: Drug insight: Antiangiogenic therapies for gastrointestinal cancers - focus on monoclonal antibodies. Nat Clin Pract Gastroenterol Hepatol 5: 250-267, 2008

13. Mullen KD, Sanyal AJ, Bass NM, Poordad FF, Sheikh MY Frederick RT, Bortey E and Forbes WP: Rifaximin is safe and well tolerated for long-term maintenance of remission from overt hepatic encephalopathy. Clin Gastroenterol Hepatol 12: 1390-1397.e1392, 2014

14. de la Cabada Bauche J and Dupont HL: New developments in traveler's diarrhea. Gastroenterol Hepatol (NY) 7: 88-95, 2011.

15. Calanni F, Renzulli C, Barbanti M and Viscomi GC: Rifaximin Beyond the traditional antibiotic activity. J Antibiot (Tokyo) 67: 667-670, 2014.

16. Cheng J, Shah YM, Ma X, Pang X, Tanaka T, Kodama T, Krausz KW and Gonzalez FJ: Therapeutic role of rifaximin in inflammatory bowel disease: Clinical implication of human pregnane X receptor activation. J Pharmacol Exp Ther 335: 32-41, 2010.

17. Mencarelli A, Renga B, Palladino G, Claudio D, Ricci P, Distrutti E, Barbanti M, Baldelli F and Fiorucci S: Inhibition of NF- $\kappa$ B by a PXR-dependent pathway mediates counter-regulatory activities of rifaximin on innate immunity in intestinal epithelial cells. Eur J Pharmacol 668: 317-324, 2011.
18. Kota BP, Tran VH, Allen J, Bebawy M and Roufogalis BD: Characterization of PXR mediated P-glycoprotein regulation in intestinal LS174T cells. Pharmacol Res 62: 426-431, 2010.

19. Mosmann T: Rapid colorimetric assay for cellular growth and survival: Application to proliferation and cytotoxicity assays. J Immunol Methods 65: 55-63, 1983.

20. Renault-Mihara F, Beuvon F, Iturrioz X, Canton B, De Bouard S, Léonard N, Mouhamad S, Sharif A, Ramos JW, Junier MP, et al: Phosphoprotein enriched in astrocytes-15 kDa expression inhibits astrocyte migration by a protein kinase $\mathrm{C}$ delta-dependent mechanism. Mol Biol Cell 17: 5141-5152, 2006.

21. Guzińska-Ustymowicz K, Pryczynicz A, Kemona A and Czyzewska J: Correlation between proliferation markers: PCNA, $\mathrm{Ki}-67, \mathrm{MCM}-2$ and antiapoptotic protein $\mathrm{Bcl}-2$ in colorectal cancer. Anticancer Res 29: 3049-3052, 2009.

22. Yang HB, Hsu PI, Chan SH, Lee JC, Shin JS and Chow NH: Growth kinetics of colorectal adenoma-carcinoma sequence: An immunohistochemical study of proliferating cell nuclear antigen expression. Hum Pathol 27: 1071-1076, 1996.

23. Cacciottolo TM, Kingdon A and Alexander GJ: Rifaximin is largely safe and well tolerated but caution is necessary when taken with statins. Clin Gastroenterol Hepatol 12: 1765, 2014.

24. Cathcart J, Pulkoski-Gross A and Cao J: Targeting matrix metalloproteinases in cancer: Bringing new life to old ideas. Genes Dis 2: 26-34, 2015.

25. Cheng J, Fang ZZ, Nagaoka K, Okamoto M, Qu A, Tanaka N, Kimura S and Gonzalez FJ: Activation of intestinal human pregnane $\mathrm{X}$ receptor protects against azoxymethane/dextran sulfate sodium-induced colon cancer. J Pharmacol Exp Ther 351: 559-567, 2014.

26. Hirota SA: Understanding the molecular mechanisms of rifaximin in the treatment of gastrointestinal disorders: A focus on the modulation of host tissue function. Mini Rev Med Chem 16: 206-217, 2015.

27. Li J and Saif MW: Current use and potential role of bevacizumab in the treatment of gastrointestinal cancers. Biologics 3: 429-441, 2009.

28. Giantonio BJ, Catalano PJ, Meropol NJ, O'Dwyer PJ, Mitchell EP, Alberts SR, Schwartz MA and Benson AB III; Eastern Cooperative Oncology Group Study E3200: Bevacizumab in combination with oxaliplatin, fluorouracil, and leucovorin (FOLFOX4) for previously treated metastatic colorectal cancer: Results from the Eastern Cooperative Oncology Group Study E3200. J Clin Oncol 25: 1539-1544, 2007.

29. Hurwitz HI, Fehrenbacher L, Hainsworth JD, Heim W, Berlin J, Holmgren E, Hambleton J, Novotny WF and Kabbinavar F: Bevacizumab in combination with fluorouracil and leucovorin: An active regimen for first-line metastatic colorectal cancer. J Clin Oncol 23: 3502-3508, 2005.

30. Jain RK: Normalizing tumor vasculature with anti-angiogenic therapy: A new paradigm for combination therapy. Nat Med 7: 987-989, 2001

31. Huber PE, Bischof M, Jenne J, Heiland S, Peschke P, Saffrich R, Gröne HJ, Debus J, Lipson KE and Abdollahi A: Trimodal cancer treatment: Beneficial effects of combined antiangiogenesis, radiation, and chemotherapy. Cancer Res 65: 3643-3655, 2005. 